\title{
Transition Metal Oxide Tubes Synthesized by Using Ammonium Tartrate Crystal Template
}

\author{
Fumiaki MIYAJI, Yoshimitsu TATEMATSU and Yoko SUYAMA \\ Department of Materials Science, Faculty of Science and Engineering, Shimane University, \\ 1060, Nishi-Kawatsu-cho, Matsue-shi, Shimane 690-8504
}

\author{
酒石酸アンモニウム結晶テンプレートを用いて合成された遷移金属酸化物チューブ \\ 宮路史明·立松由光・陶山容子 \\ 島根大学総合理工学部物質科学科, 690-8504 島根県松江市西川津町 1060
}

\begin{abstract}
Transition metal oxide $\left(\mathrm{TiO}_{2}, \mathrm{ZrO}_{2}, \mathrm{Nb}_{2} \mathrm{O}_{5}\right.$ and $\mathrm{Ta}_{2} \mathrm{O}_{5}$ ) tubes were synthesized by using organic crystal with needle-like form i.e. ammonium $d l$-tartrate as a template in sol-gel reaction. First, ammonium $d l$-tartrate crystals were precipitated and rapidly grown to needle-like form when concentrated ammonia was added to ethanol solution containing $d l$-tartaric acid. Next, the transition metal oxide was deposited only on the side faces of the template crystals when corresponding metal alkoxide was added into the ethanol solution containing the crystal templates and stirred. After deposition of the oxide layer on the side faces of the crystals, the central templates were removed by washing with water to form hollow tubes with rectangular outer shapes and inner channels. The size of the thus formed tubes were $c a .40-200 \mu \mathrm{m}$ in length, $1.3-5.9 \mu \mathrm{m}$ in width, 1.0-4.9 $\mu \mathrm{m}$ in channel width and $0.2-0.7 \mu \mathrm{m}$ in wall thickness. It was found from FT-IR and powder XRD that every kind of tube was present as amorphous oxide gel. The specific surface areas and pore size distribution of as-prepared tubes significantly varied depending on the kind of alkoxides. The uniformity of hydrolytic polycondensation of alkoxides and the amount of hydrated water in gel might affect the microporous structure of the tubes. The present template method using water-soluble ammonium $d l$-tartrate crystal could be effective for synthesizing micron-submicron sized transition metal oxide tubes according to a simple process.

[Received June 11, 2001; Accepted August 9, 2001]
\end{abstract}

Key-words : Transition metal oxide, Tube, Template, Ammonium tartrate, Sol-gel, Specific surface area

\section{Introduction}

Tubular materials are attracting much attention since carbon nanotube was found by Iijima. ${ }^{1)}$ Since then, various other inorganic hollow tubes have been exploited for boron nitride, ${ }^{2), 3)}$ silica, ${ }^{4)-8)}$ titania, ${ }^{9)}{ }^{\text {(12) }}$ vanadium oxide ${ }^{13)}$ and so on, although their dimensions are widely varied. Unique tubular structures are potentially useful for applications such as catalyst carriers, sensors, electronic devices and storage and release systems. ${ }^{8), 13)}$

On the other hand, the template-directed sol-gel synthesis of inorganic materials can give wide-ranging materials with various external shapes and internal structures. The mesoporous silica MCM41 first developed by Mobil is one of the most successful examples of controlled structure. ${ }^{14)}$ In this case surfactant assemblies acts as a template for hexagonally packed mesopores. As for synthesis of tubular materials, various organic and inorganic templates have been used associated with sol-gel synthesis. For example, hollow tubes of amorphous silica have been prepared by using the external surface of self-assembled phospholipid fibers, ${ }^{4)}$ organic gel filaments, ${ }^{5}$ ) viroid cylinders, ${ }^{6)}$ anodic alumina nano-array, ${ }^{7)}$ and cylindrical assemblies of surfactant. ${ }^{8)}$

The use of such specialized molecules or arrays mentioned above, however, has the potential drawback that the costs associated with scale-up are likely to be highly prohibitive. Thus, the process by Nakamura and Matsui on the formation of silica tubes from $\mathrm{C}_{2} \mathrm{H}_{5} \mathrm{OH} / \mathrm{H}_{2} \mathrm{O} / \mathrm{NH}_{3}$ aq./ $\mathrm{Si}\left(\mathrm{OC}_{2} \mathrm{H}_{5}\right)_{4}$ (tetraethyl orthosilicate; TEOS) mixtures that contained a small amount of a simple organic acid (for example, racemic $d l$-tartaric acid), is particularly interesting. ${ }^{15)}$ Although they speculated that the chains of hydrogen-bonded $d l$-tartaric acid molecules act as a template for the deposition of the silica tube, the present authors clarified that needle-like ammonium $d l$-tartrate crystal, which is formed almost simultaneously with polycondensed silica when $\mathrm{NH}_{3}$ aq. is added, play a role of template. ${ }^{16)}$ The key in this templating process, is a dual role of $\mathrm{NH}_{3}$ aq., which acts not only as a source of the template crystal but also as a basic catalyst for silica hydrolysis and polycondensation. In the present work, the validity of ammonium $d l$-tartrate for templating tubes of various transition metal oxides $\left(\mathrm{TiO}_{2}, \mathrm{ZrO}_{2}, \mathrm{Nb}_{2} \mathrm{O}_{5}\right.$ and $\left.\mathrm{Ta}_{2} \mathrm{O}_{5}\right)$ was examined and the tubes formed were characterized.

\section{Experimental procedure}

Typically, $0.05 \mathrm{~g}$ of $d l$-tartaric acid (Tokyo Kasei Kogyo Co., Ltd.) was dissolved into $5 \mathrm{ml}$ of $\mathrm{C}_{2} \mathrm{H}_{5} \mathrm{OH}$ (Kanto Chemical Co., Inc.). Subsequently, $2 \mathrm{ml}$ of $28 \% \mathrm{NH}_{3}$ aq. (Kanto Chemical Co., Inc.) was added to the ethanol solution, and the solution was allowed to stand for $5 \mathrm{~min}$ to precipitate and grow needle-like ammonium $d l$-tartrate crystals. The template crystals formed were washed with $\mathrm{C}_{2} \mathrm{H}_{5} \mathrm{OH}$ for removing excess $\mathrm{NH}_{3}$ aq. Into the ethanol solution $(1-7 \mathrm{ml})$ containing the template crystals, $0.5 \mathrm{ml}$ of titanium(IV) tetra- $n$-butoxide $\left(\mathrm{Ti}\left(\mathrm{OC}_{4} \mathrm{H}_{9}{ }^{n}\right)_{4}\right.$; Aldrich Chemical Co., Inc.), zirconium (IV) tetra- $n$-propoxide $\left(\mathrm{Zr}\left(\mathrm{OC}_{3} \mathrm{H}_{7}^{n}\right)_{4} ; \mathrm{Al}\right.$ drich Chemical Co., Inc.), niobium(V) pentaethoxide $\left(\mathrm{Nb}\left(\mathrm{OC}_{2} \mathrm{H}_{5}\right)_{5}\right.$; Wako Pure Chemical Industries, Ltd.) or tantalum (V) pentaethoxide $\left(\mathrm{Ta}\left(\mathrm{OC}_{2} \mathrm{H}_{5}\right)_{5}\right.$; Wako Pure Chemical Industries, Ltd.) was added and the solution was stirred at $25-60^{\circ} \mathrm{C}$ for $1-60 \mathrm{~h}$. For comparison, the process similar to one used in the previous silica tube synthesis ${ }^{16)}$ was also tried for titania. That is, $0.5 \mathrm{ml}$ of $\mathrm{Ti}\left(\mathrm{OC}_{4} \mathrm{H}_{9}{ }^{n}\right)_{4}$ was added into $5 \mathrm{ml}$ of $\mathrm{C}_{2} \mathrm{H}_{5} \mathrm{OH}$ containing $0.05 \mathrm{~g}$ of $d l$-tartaric acid, and the mixed solution was allowed to stand for 0-30 min. Subsequently, $2 \mathrm{ml}$ of $28 \% \mathrm{NH}_{3}$ aq. was added to the solution and the solution was allowed to stand for 5-30 min. 
All the products were washed with a large amount of water on a test sieve with $63 \mu \mathrm{m}$ aperture, or unwashed. In case of unwashed samples, products were collected on a 0.2 $\mu \mathrm{m}$ membrane filter. The samples thus obtained were dried at room temperature for $72 \mathrm{~h}$ and subjected to SEM observation (HITACHI, S-2500CX), FT-IR spectra measurement (Nippon Bunko, FT/IR-620), powder XRD measurement (Rigaku, RINT-2000) and TG-DTA (Rigaku, TG8120). The $\mathrm{N}_{2}$ adsorption isotherms were measured for washed samples (Quantachrome, AUTOSORB-1). Prior to measurements, all the samples were outgassed at $100^{\circ} \mathrm{C}$ for $3 \mathrm{~h}$. The BET specific surface areas and pore size distributions (SF method) were calculated for each sample.

As-dried samples were heated to given temperatures at

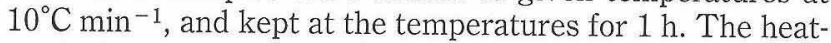
treated samples were subjected to powder XRD and the $\mathrm{N}_{2}$ adsorption measurements.

\subsection{Tube formation}

\section{Results and discussion}

When $\mathrm{Ti}\left(\mathrm{OC}_{4} \mathrm{H}_{9}{ }^{n}\right)_{4}$ was added into $\mathrm{C}_{2} \mathrm{H}_{5} \mathrm{OH}$ containing $d l$-tartaric acid prior to $\mathrm{NH}_{3}$ aq. addition, aggregates of $\mathrm{TiO}_{2}$ gel were immediately formed on addition of $\mathrm{NH}_{3}$ aq. No tube formation was observed regardless of time allowed to be passed after $\mathrm{Ti}\left(\mathrm{OC}_{4} \mathrm{H}_{9}{ }^{n}\right)_{4}$ and/or $\mathrm{NH}_{3}$ aq. addition. Similar results were observed for the other alkoxides. These results indicate that the process used in silica tube synthesis is not effective for formation of transition metal oxide tubes. The transition metal alkoxides used in this work are hydrolyzed and polycondensed to form the aggregates before the formation of template crystal when $\mathrm{NH}_{3}$ aq. is added, since the rates of hydrolysis and polycondensation are much higher in transition metal alkoxides than in TEOS used in the previous work.

Thus, the template crystals were made to be formed prior to alkoxide addition in all the syntheses of transition metal oxide tubes hereafter. White colloidal particles were immediately formed for every alkoxide and no tube was formed if the removal of excess $\mathrm{NH}_{3}$ aq. from the ethanol solution containing the template crystals was insufficient. This documents the extreme reactivity of transition metal alkoxides with water under basic condition. When $\mathrm{NH}_{3}$ aq. removal from the ethanol solution was almost complete, hydrolysis of transition metal alkoxide gradually proceeded by water in air. The control of both the reaction temperature and time enabled all the oxides used in this work to form hollow tubes. The favorable reaction temperature and time for tube formation were $25-40^{\circ} \mathrm{C}$ and $2-3 \mathrm{~h}$, respectively, for all kinds of the oxide tubes. Generally, the increased temperature $\left(>40^{\circ} \mathrm{C}\right)$ and prolonged reaction time $(>3 \mathrm{~h})$ cause preferential formation of colloidal particles for all the oxides because they enhance the polycondensation of the hydrolyzed species. As a result, the amount of the particles attached to the outer walls of the tubes increased with increasing reaction time. The relatively low reaction temperature and short reaction time are favorable for the formation of tubes with less surface-attached particles. In addition, too much dilution of the template solution with ethanol lowered the yield of tubes. The decrease in frequency of collision of hydrolyzed species with crystal templates might retard the growth of tube wall.

Figure 1 shows the SEM photographs of various oxide tubes. The tubes had rectangular-shaped channels with $40-200 \mu \mathrm{m}$ in length, $1.3-5.9 \mu \mathrm{m}$ in width, $1.0-4.9 \mu \mathrm{m}$ in channel width and $0.2-0.7 \mu \mathrm{m}$ in wall thickness. Under SEM observation, the edges of the tubes were all opened, and no closed edges were found. In the formation of silica tubes, where TEOS was added to the solution prior to $\mathrm{NH}_{3}$ aq. addition, the formed tubes were typically $200-300 \mu \mathrm{m}$ in
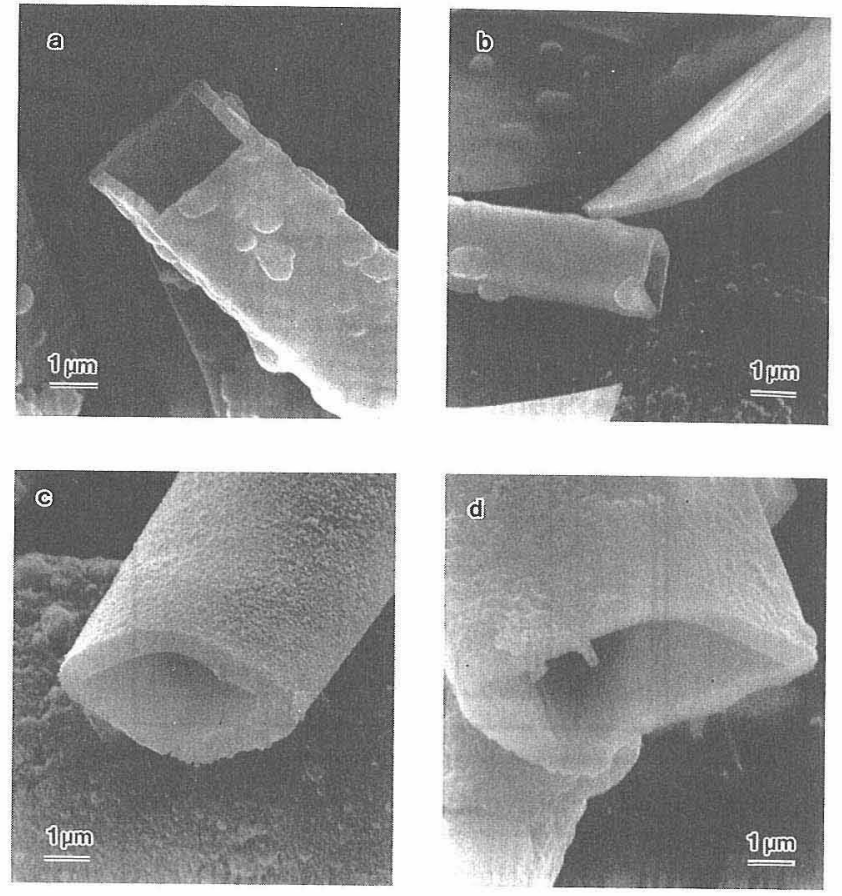

Fig. 1. SEM photograph of various transition metal oxide tubes. (a) $\mathrm{TiO}_{2}$, (b) $\mathrm{ZrO}_{2}$, (c) $\mathrm{Nb}_{2} \mathrm{O}_{5}$, (d) $\mathrm{Ta}_{2} \mathrm{O}_{5}$.

length, $0.1-1 \mu \mathrm{m}$ in width, $0.1-0.8 \mu \mathrm{m}$ in channel width and 20-300 $\mathrm{nm}$ in wall thickness. ${ }^{16)}$ The larger size of transition metal oxide tubes in this work than that of previous silica tubes is attributed to the difference in size of the template crystals. The former oxides were deposited on well-grown ammonium $d l$-tartrate crystals (ca. $1-10 \mu \mathrm{m}$ in width), whereas silica deposition occurred almost simultaneously with the crystal precipitation. ${ }^{16)}$ The silica deposition on the side faces of the template crystals disturbs the crystal growth over about $1 \mu \mathrm{m}$ in width. The bending shape of silica tubes also suggests the strong influence of deposited silica species on the stage of growth of ammonium $d l$-tartrate, although all the transition metal oxide tubes are not bending but straight.

\subsection{Process of templating tubes}

Figures 2 and 3 show powder XRD patterns and FT-IR spectra of the ammonium $d l$-tartrate crystals precipitated from ethanol containing $d l$-tartaric acid on addition of $\mathrm{NH}_{3}$ aq., the unwashed $\mathrm{TiO}_{2}$ tubes collected on a $0.2 \mu \mathrm{m}$ membrane filter, and the $\mathrm{TiO}_{2}$ tubes washed with a large amount of water and collected on a $63 \mu \mathrm{m}$-aperture test sieve. Powder XRD patterns of both the washed and unwashed $\mathrm{TiO}_{2}$ tubes showed a broad peak centered at $2 \theta=22^{\circ}$, corresponding to amorphous $\mathrm{TiO}_{2}$ gel, but only the latter showed significant peaks at $2 \theta=21.3^{\circ}$ and $33.1^{\circ}$. These reflections were also present as intense peaks in the powder XRD pattern recorded on pure ammonium $d l$-tartrate crystals. Similarly, FT-IR spectrum of the unwashed tubes showed characteristic absorption bands for tartrate at 1075 and $1130 \mathrm{~cm}^{-1}$, which were absent for the washed tubes. The broad band ascribed to $\mathrm{TiO}_{2}$ was observed at about 400-900 $\mathrm{cm}^{-1}$. Figure 4 shows the TG-DTA profiles of (a) the ammonium $d l$-tartrate template, and (b) the unwashed and (c) washed $\mathrm{TiO}_{2}$ tubes. The TG profile of the template showed distinct weight loss (ca.60\%) between 200 and $250^{\circ} \mathrm{C}$. This significant weight loss corresponds to a large endothermic peak ascribed to thermal decomposition of the organic crystal template. The template was completely decomposed be- 


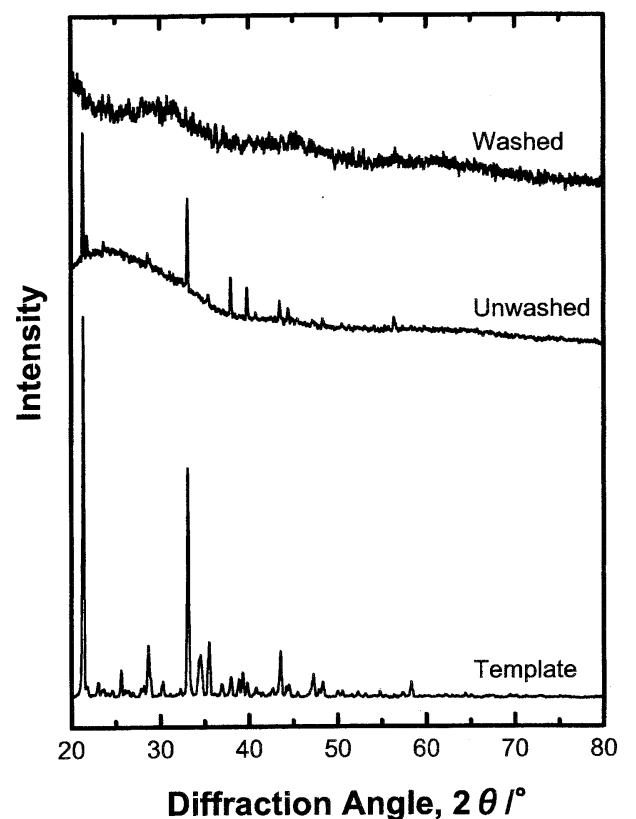

Fig. 2. Powder XRD patterns of ammonium $d l$-tartrate crystal template, unwashed and washed $\mathrm{TiO}_{2}$ tubes.

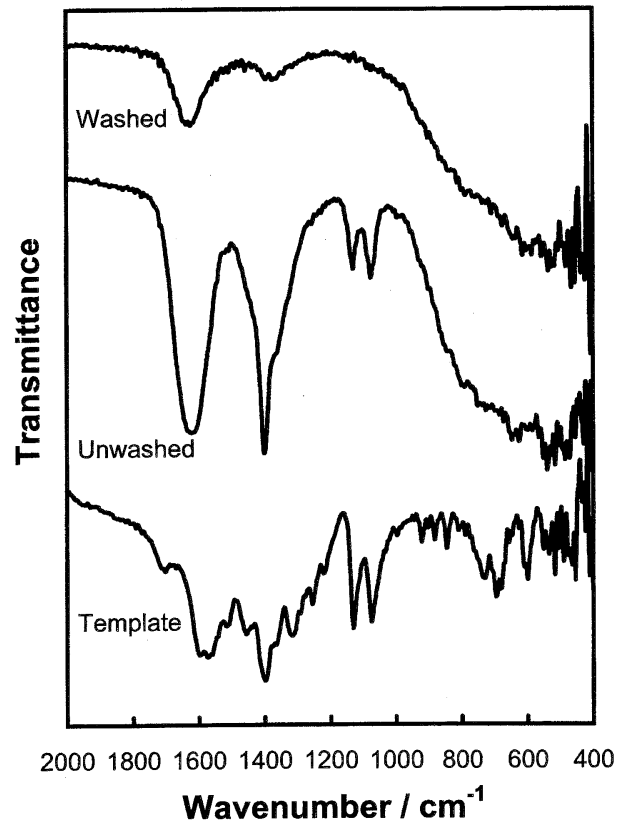

Fig. 3. FT-IR spectra of ammonium $d l$-tartrate crystal template, unwashed and washed $\mathrm{TiO}_{2}$ tubes.
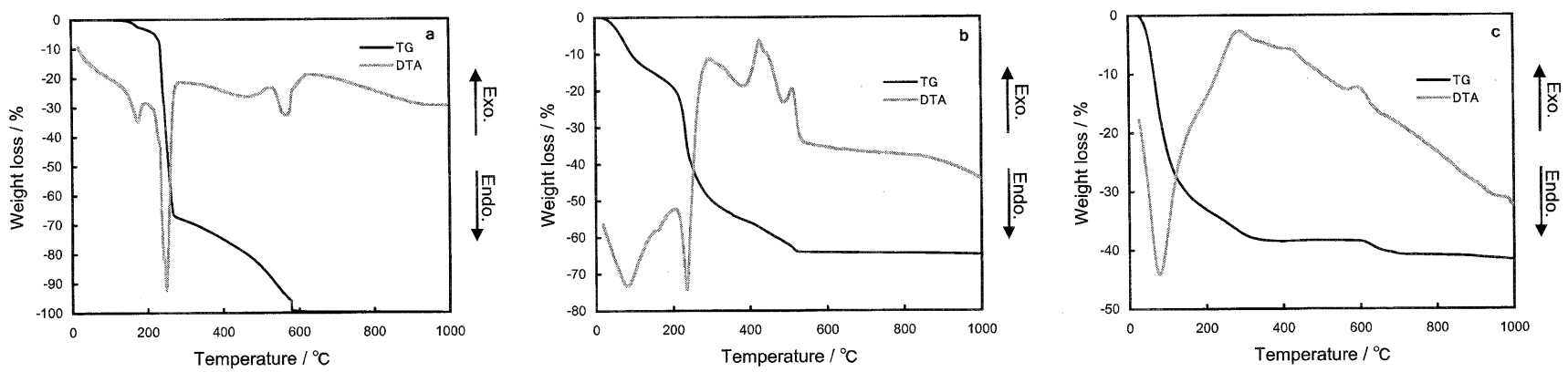

Fig. 4. TG-DTA profiles of (a) ammonium $d l$-tartrate crystal template, (b) unwashed and (c) washed $\mathrm{TiO}_{2}$ tubes.

low $600^{\circ} \mathrm{C}$. Such distinct weight loss between 200 and $250^{\circ} \mathrm{C}$ was also observed for the unwashed tubes, since they contained a large amount of the crystal template. Regarding the unwashed tube, a few distinct exothermic peaks appeared between 300 and $550^{\circ} \mathrm{C}$ in the DTA profile. These peaks might be attributed to combustion of organic residues of polymerized species. Since the alkoxide was hydrolyzed in the presence of quite a small amount of water, it is plausible that a fair proportion of alkoxide was not completely hydrolyzed. On the other hand, distinct weight loss was not observed between 200 and $250^{\circ} \mathrm{C}$ but observed around $100^{\circ} \mathrm{C}$ in the TG profile of the washed tubes. About 25\% weight loss and large endothermic peak around $100^{\circ} \mathrm{C}$ are ascribed to dehydration of $\mathrm{TiO}_{2}$ gel. Exothermic peaks between 300 and $550^{\circ} \mathrm{C}$, which were distinct for the unwashed tubes, were diminished for the washed tubes. This suggests that organic residues of polymerized species decreased by washing the tubes with a large amount of water.

Similar results were obtained for the other oxide tubes with respect to SEM, powder XRD, FT-IR and TG-DTA. Figure 5 schematically shows the possible mechanism of tube formation for $\mathrm{TiO}_{2}$ as a representative. Ammonium $d l$ tartrate template crystals with needle-like form are precipi- tated from ethanol containing $d l$-tartaric acid on addition of $\mathrm{NH}_{3}$ aq., since the solubility of ammonium $d l$-tartrate in ethanol is quite low. ${ }^{16)}$ Titanium alkoxide is gradually hydrolyzed with water from air and polycondensed on the crystal templates. In this case, $\mathrm{TiO}_{2}$ is deposited only on the side faces of the crystal, similarly to $\mathrm{SiO}_{2}$. This leads to hollow tube formation by washing out of central crystal template with water.

One question is why the edges of the template crystals are remained uncoated with $\mathrm{TiO}_{2}$. One possible explanation is concerned with preferential re-dissolution of crystal template along $a$-axis. Although ammonium $d l$-tartrate crystal rapidly grows with layer-by-layer assembly of $\mathrm{NH}_{4}{ }^{+}$and tartrate ions along its $a$-axis, they re-dissolve in part with water produced locally from polycondensed alkoxide. If the rate of re-dissolution of the crystal along $a$-axis is higher than that of $\mathrm{TiO}_{2}$ deposition to be a stable layer, the end faces of the crystal would be remained uncoated with $\mathrm{TiO}_{2}$. The length of transition metal oxide tubes was short rather than that of silica tubes in spite of larger width of the former than the latter. This discrepancy may also support the rapid re-dissolution of ammonium $d l$-tartrate along $a$-axis. One might assume that the operation of stirring and washing may cause 


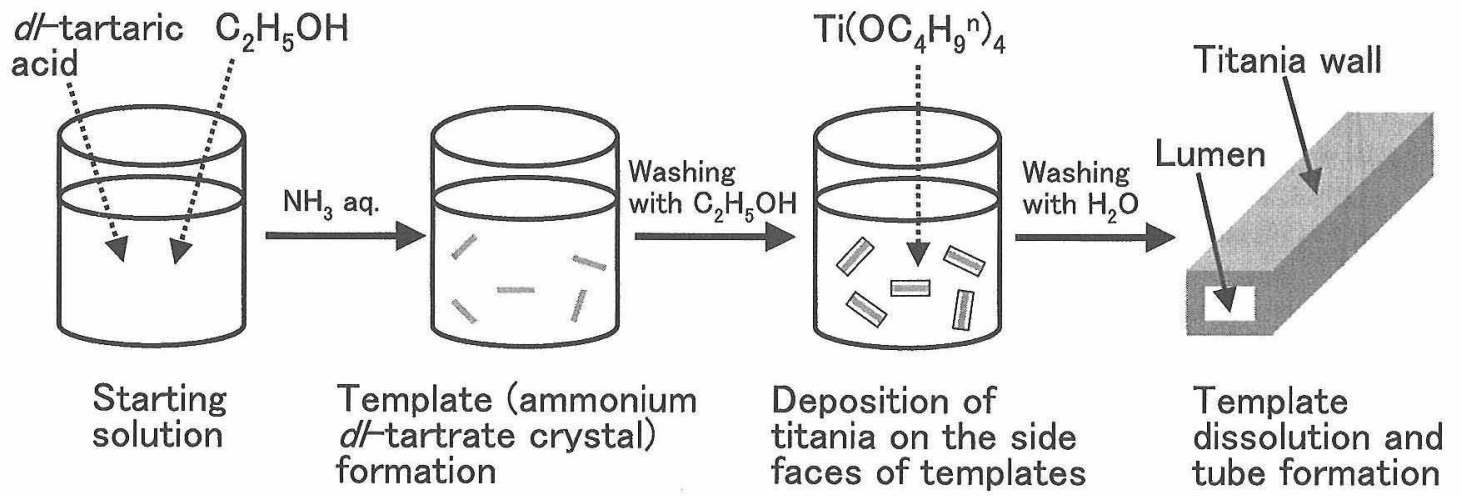

Fig. 5. Process of $\mathrm{TiO}_{2}$ tube formation using ammonium $d l$-tartrate crystal template.

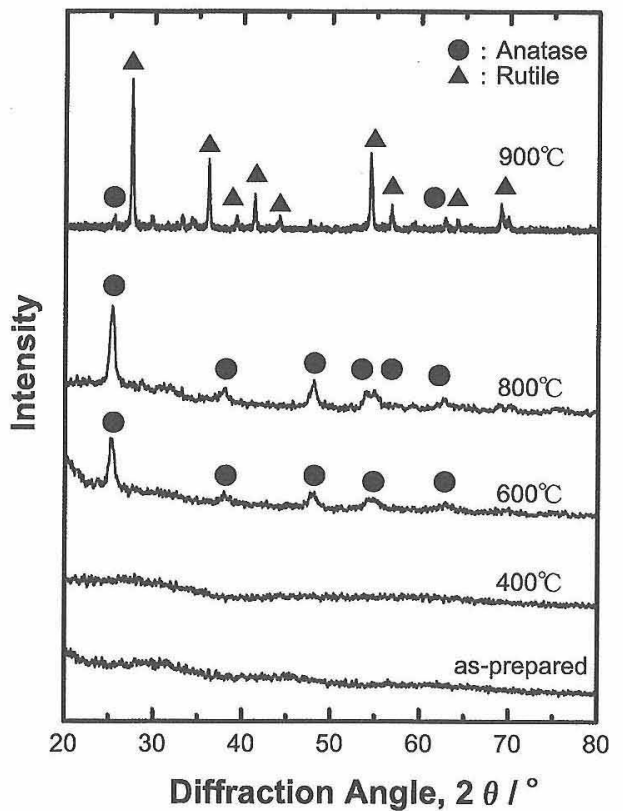

Fig. 6. Powder XRD patterns of $\mathrm{TiO}_{2}$ tubes heat-treated at various temperatures for $1 \mathrm{~h}$.

the breakage of crystals and resultant tubes with opened edges. This is, however, not the case, since the tubes with closed edges were not found at all.

3.3 Characterization of tubes

Figure 6 shows the powder XRD patterns of the $\mathrm{TiO}_{2}$ tubes heat-treated at various temperatures for $1 \mathrm{~h}$. Most of the tubes retained their tubular form without breakage even after heat treatment. While $\mathrm{TiO}_{2}$ tubes were amorphous below $400^{\circ} \mathrm{C}$, anatase phase started to appear at $600^{\circ} \mathrm{C}$ and increased its XRD peak intensity at $800^{\circ} \mathrm{C}$. Rutile phase became predominant at $900^{\circ} \mathrm{C}$. Appearance of anatase phase at $600^{\circ} \mathrm{C}$ indicates that the small exothermic peak and weight loss at about at $600^{\circ} \mathrm{C}$ in the TG-DTA profile of washed $\mathrm{TiO}_{2}$ tube (Fig. 4(c)) is ascribed to phase transformation (crystallization). Table 1 shows the specific surface areas of the as-prepared and heat-treated tubes. The specific surface area of $\mathrm{TiO}_{2}$ tube is exceptionally larger than those of the other tubes. This might be attributed to the formation of $\mathrm{TiO}_{2}$ gel containing a large amount of hydrated water. It was found from TG profiles that $\mathrm{TiO}_{2}$ tubes and the other oxide tubes show about 25\% and 15\% weight loss up to
Table 1. Specific Surface Areas of As-Prepared and Heat-Treated Tubes

\begin{tabular}{ccc}
\hline Tube & & Surface area $/ \mathrm{m}^{2} \mathrm{~g}^{-1}$ \\
\hline $\mathrm{TiO}_{2}$ & As-prepared & 394 \\
& $500^{\circ} \mathrm{C}$ & 109 \\
& $700^{\circ} \mathrm{C}$ & 16.7 \\
& $900^{\circ} \mathrm{C}$ & 13.5 \\
& & 87.5 \\
$\mathrm{ZrO}_{2}$ & As-prepared & 12.0 \\
& $700^{\circ} \mathrm{C}$ & 81.6 \\
$\mathrm{Nb}_{2} \mathrm{O}_{5}$ & As-prepared & 12.8 \\
& $700^{\circ} \mathrm{C}$ & 57.1 \\
$\mathrm{Ta}_{2} \mathrm{O}_{5}$ & As-prepared & 20.9 \\
& $700^{\circ} \mathrm{C}$ & \\
\hline
\end{tabular}

$100^{\circ} \mathrm{C}$ due to dehydration, respectively. This suggests that larger amount of micropores exist in $\mathrm{TiO}_{2}$ tubes than in the other oxide tubes. Figure 7 shows the pore size distribution of the as-prepared and $700^{\circ} \mathrm{C}$-treated (a) $\mathrm{TiO}_{2}$ and (b) $\mathrm{ZrO}_{2}$ tubes. As shown in Fig. 7(a), the pore size distribution of as-prepared $\mathrm{TiO}_{2}$ tube is very broad around $0.6 \mathrm{~nm}$. The broad distribution of micropore may reflect the different degree of hydrolytic polycondensation of $\mathrm{Ti}\left(\mathrm{OC}_{4} \mathrm{H}_{9}{ }^{n}\right)_{4}$. On the contrary, the pore size distribution of as-prepared $\mathrm{ZrO}_{2}$ tubes is much sharper than that of as-prepared $\mathrm{TiO}_{2}$, as shown in Fig. 7 (b). This suggests that hydrolysis and poly-

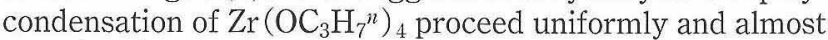
completed, resulting in sharp distribution of micropores. By heat treatment at $700^{\circ} \mathrm{C}$, micropores almost disappeared not only for $\mathrm{TiO}_{2}$ and $\mathrm{ZrO}_{2}$ tubes but also for the other tubes, consistent with similar surface specific areas as low as $10-20 \mathrm{~m}^{2} \cdot \mathrm{g}^{-1}$.

\section{Conclusion}

Synthesis of transition metal oxide tubes was attempted by using organic crystal templates. Ammonium $d l$-tartrate crystal with needle-like form was effective for templating the tubes of various transition metal oxides $\left(\mathrm{TiO}_{2}, \mathrm{ZrO}_{2}\right.$, $\mathrm{Nb}_{2} \mathrm{O}_{5}$ and $\mathrm{Ta}_{2} \mathrm{O}_{5}$ ). Oxide gel tubes with rectangular outer shapes and inner channels were formed. The tube formation was assumed to be proceed via deposition of hydrolytic species of each alkoxide on the side faces of the template crystals and subsequent dissolution of the central templates. 

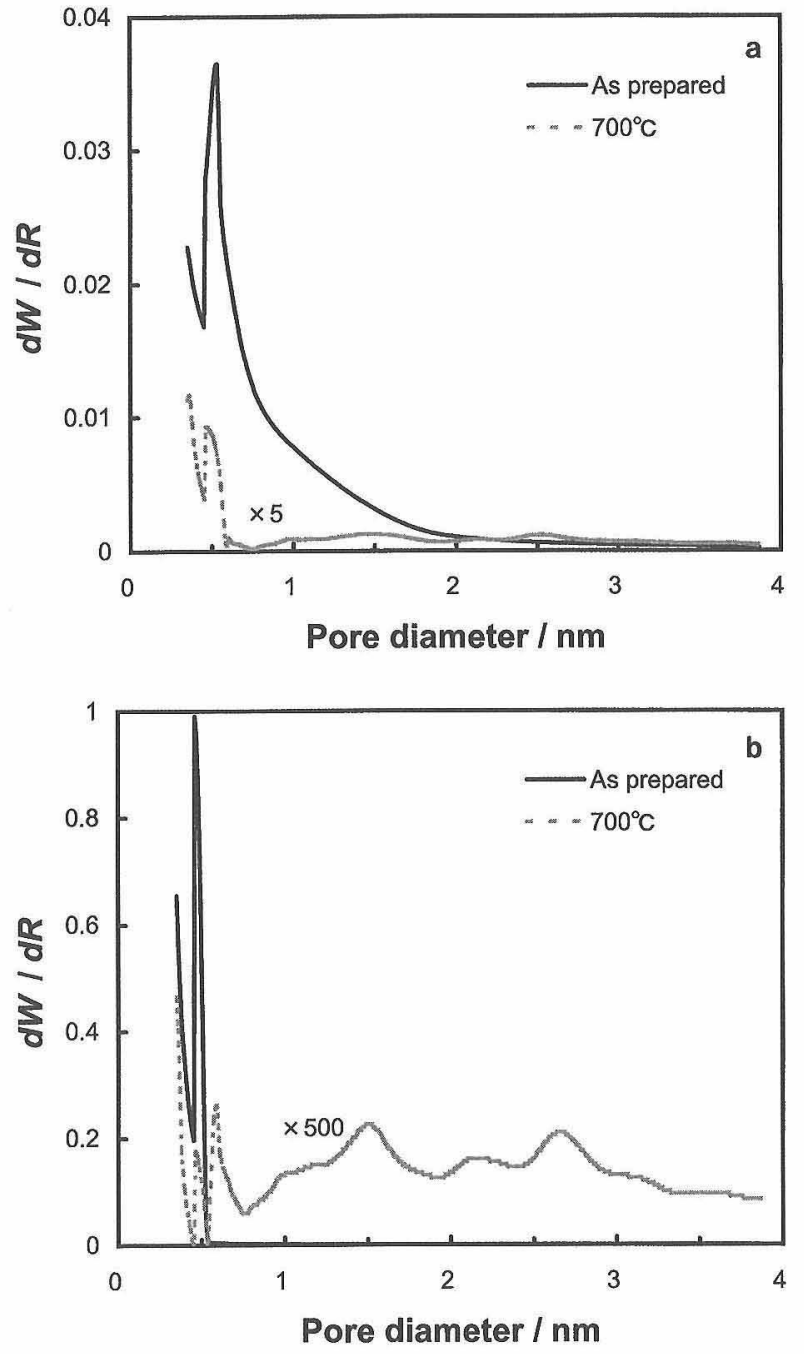

Fig. 7. Pore size distribution of as-prepared and heat-treated $\left(700^{\circ} \mathrm{C}, 1 \mathrm{~h}\right.$ ) tubes. (a) $\mathrm{TiO}_{2}$ and (b) $\mathrm{ZrO}_{2}$.
Thus, the present template method using ammonium $d l$-tartrate crystal could be generally effective for synthesizing micron-submicron sized transition metal oxide tubes.

Acknowledgment This work was supported by the Grant-inAid for Scientific Research from the Ministry of Education, Culture, Sports, Science and Technology of Japan (No. 12750603).

\section{References}

1) Iijima, S., Nature, 354, 56-58 (1991).

2) Hamilton, E. J. M., Dolan, S. E., Mann, C. M., Coloijin, H. O., McDonald, C. A. and Shore, S. G., Science, 260, 659-61 (1993).

3) Gleize, P., Shouler, M. C., Gadelle, P. and Gaillet, M., J. Mater. Sci., 29, 1575-80 (1994).

4) Baral, S. and Schoen, S., Chem. Mater., 5, 145-47 (1992).

5) Ono, Y., Nakashima, K., Sano, M., Kanekiyo, Y., Inoue, K., Hojo, J. and Shinkai, S., Chem. Commun., 1477-78 (1998).

6) Shenton, W., Douglas, T., Young, M., Stubbs, G. and Mann, S., Adv. Mater., 11, 253-56 (1999).

7) Zhang, M., Bando, Y. and Wada, K., J. Mater. Res., 15, 387-92 (2000).

8) Harada, M. and Adachi, M., Adv. Mater., 12, 839-41 (2000).

9) Hoyer, P., Langmuir, 12, 1411-13 (1996).

10) Kasuga, T., Hiramatsu, M., Hoson, A., Sekino, T. and Niihara, K., Langmuir, 14, 3160-63 (1998).

11) Imai, H., Takei, Y., Shimizu, K., Matsuda, M. and Hirashima, H., J. Mater. Chem., 9, 2971-72 (1999).

12) Kobayashi, S., Hanabusa, K., Hamasaki, N., Kimura, M. and Shirai, H., Chem. Mater., 12, 1523-25 (2000).

13) Muhr, H. J., Krumeich, F., Schönholzer, U. P., Bieri, F. Niederberger, M., Gauckler, L. J. and Nesper, R., $A d v$. Mater., 12, 231-33 (2000).

14) Kresge, C. T., Lenowicz, M. E., Roth, W. J., Vartuli, J. C. and Beck, J.S., Nature, 359, 710-12 (1992).

15) Nakamura, H. and Matsui, Y., Adv. Mater., 7, 871-72 (1995).

16) Miyaji, F., Davis, S. A., Charmant, J. P. H. and Mann, S., Chem. Mater., 11, 3021-24 (1999). 